\title{
Article
}

\section{The Combined Use of Remote Sensing and Wireless Sensor Network to Estimate Soil Moisture in Golf Course}

\author{
Pedro V. Mauri ${ }^{1}\left(\mathbb{D}\right.$, Lorena Parra ${ }^{1,2, *(\mathbb{D})}$, David Mostaza-Colado ${ }^{1}\left(\mathbb{D}\right.$, Laura Garcia ${ }^{2}$, , Jaime Lloret $^{2}$ (D) \\ and Jose F. Marin ${ }^{3}$ (D)
}

1 Instituto Madrileño de Investigación y Desarrollo Rural, Agrario y Alimentario (IMIDRA), Finca "El Encin", A-2, Km 38, 2, 28805 Alcalá de Henares, Spain; pedro.mauri@madrid.org (P.V.M.); david.mostaza@madrid.org (D.M.-C.)

2 Instituto de Investigación para la Gestión Integrada de Zonas Costeras, Universitat Politècnica de València, Grao de Gandía, 46730 Valencia, Spain; laugarg2@teleco.upv.es (L.G.); jlloret@dcom.upv.es (J.L.)

3 Area Verde MG Projects S.L. C/Oña, 43, 28933 Madrid, Spain; jmarin@areaverde.es

* Correspondence: loparbo@doctor.upv.es

Citation: Mauri, P.V.; Parra, L.; Mostaza-Colado, D.; Garcia, L.; Lloret, J.; Marin, J.F. The Combined Use of Remote Sensing and Wireless Sensor Network to Estimate Soil Moisture in Golf Course. Appl. Sci. 2021, 11, 11769. https://doi.org/10.3390/app 112411769

Academic Editor: Seong-Jik Park

Received: 3 November 2021

Accepted: 5 December 2021

Published: 10 December 2021

Publisher's Note: MDPI stays neutral with regard to jurisdictional claims in published maps and institutional affiliations.

Copyright: (c) 2021 by the authors. Licensee MDPI, Basel, Switzerland. This article is an open access article distributed under the terms and conditions of the Creative Commons Attribution (CC BY) license (https:// creativecommons.org/licenses/by/ $4.0 /)$.

\begin{abstract}
In gardening, particularly in golf courses, soil moisture management is critical for maximizing water efficiency. Remote sensing has been used to estimate soil moisture in recent years with relatively low accuracies. In this paper, we aim to use remote sensing and wireless sensor networks to generate soil moisture indexes for a golf course. In the golf course, we identified three types of soil, and data was gathered for three months. Mathematical models were obtained using data from Sentinel-2, bands with a resolution of 10 and $20 \mathrm{~m}$, and sensed soil moisture. Models with acceptable accuracy were obtained only for one out of three soil types, the natural soil in which natural vegetation is grown. Two multiple regression models are presented with an $\mathrm{R}^{2}$ of 0.46 for bands at $10 \mathrm{~m}$ and 0.70 for bands at $20 \mathrm{~m}$. Their mean absolute error was lower than $3 \%$ in both cases. For the modified soils, the greens, and the golf course fairway, it was not feasible to obtain regression models due to the temporal uniformity of the grass and the range of variation of soil moisture. The developed moisture indexes were compared with existing options. The attained accuracies improve the current models. The verification indicates that the model generated with band 4 and band 12 is the one with better accuracy.
\end{abstract}

Keywords: Sentinel-2; soil texture; multiple regression model; water efficiency; irrigation

\section{Introduction}

The irrigation of golf courses presents important difficulties due to the heterogeneous distribution of the terrain, the variations in soil composition at different areas, and high water consumption. Furthermore, some areas of the world may present added difficulties due to water scarcity, which may lead to the use of treated wastewater to irrigate the golf course [1]. Therefore, it is necessary to improve the efficiency of the irrigation to both reduce water consumption and increase the quality of the grass at the golf courses. Golf courses are comprised of differentiated areas such as the green, the fairway, or the rough. These areas have different grass lengths, and the activities performed in each area may lead to varied hazards such as uprooting [2]. The differences between these areas in vegetation, soil composition, and terrain lead to different irrigation needs. Nowadays, the popular irrigation methods of golf courses in Spain are comprised of sprinkler systems where the control options allow either the management of sprinkler lines as a group or, in some cases, the individualized management of the sprinklers. However, in order to adjust the amount of irrigation for each area or sprinkler, the soil moisture at each part of the golf course must be monitored.

The soil moisture monitoring process can be performed with varied methodologies. The use of sensors is one of the most utilized forms of soil moisture monitoring [3]. The 
most utilized soil moisture sensors are capacitance sensors. Multiple capacitance soil moisture sensors are available in the market and have been tested for different types of soils to determine their calibration equations [4]. Solid-state resistance soil moisture sensors are also available, but they are less utilized [5]. These sensors are placed at multiple depths to assess the water content in the plant's root zone. The methodology of deploying soil multiple soil moisture sensors is widely used for precision agriculture and has been extended to other types of environments such as urban lawns and golf courses [6]. The staff of the golf course may perform measures by physically accessing the desired area. On the other hand, the sensors may be deployed on the golf courses to obtain soil moisture values periodically. However, this solution presents increased cost as the number of deployed sensors would determine the precision acquired for each area. As it was previously noted, the variations in the terrain lead to areas where the water is accumulated and areas with slopes where the water does not reach the desired depth. The differences in soil moisture content of these different types of areas are difficult to monitor with sensors because it would require a great number of them. Therefore, to obtain a very detailed soil moisture map, countless sensors should be deployed in addition to the network devices necessary to transmit the data to the database. As a result, remote sensing solutions were studied to reduce the cost and difficulties of the sensor deployments.

One of the options is the use of drones that obtain images of the fields through devices such as multispectral cameras [7]. These images are then processed to obtain the soil moisture of the fields [8]. Hybrid systems that perform remote sensing through drones and use the drone as a mobile gateway to obtain the data from sensors deployed on the fields are a feasible option as well [9]. The other option is the use of satellites that provide useful data, such as images and microwave data from satellite sensors, and process it to obtain different metrics regarding the soil moisture content and the state of the plants [10]. The advantage of using satellite data is the obtention of a detailed map where the soil moisture is assessed for all the terrain without the difficulties due to the variations in the terrain faced by the sensor deployments. There are different types of available satellites to choose from, such as Sentinel or Landsat. The cost of utilizing these types of solutions may be reduced as the obtention of images from satellites such as Sentinel are free of charge. Furthermore, the spatial resolution of $10 \mathrm{~m}$ pixel size provided by Sentinel is adequate to monitor soil moisture. Other satellites may present different resolutions. Therefore, the characteristics of each satellite should be studied before deciding on which resources to use.

The contribution of this paper is the obtention of soil moisture indexes specific for the studied region to monitor soil moisture in a golf course and its surroundings by utilizing correlating sensors' data with satellite information. The currently available indexes are developed for other regions, and their accuracies are low. Nine sensors were deployed on three types of soil for approximately three months. The sensors were calibrated for each type of soil ranging from clay soil to soil with both clay and sand. Sentinel images were obtained for the same time period to assess its adequacy for soil moisture monitoring of golf courses. Furthermore, the need for the satellite to be calibrated as well according to each soil type was evaluated as well. The main objectives of this study are twofold. Firstly, we aim to obtain a training dataset with the data from both sensors and satellites and a validation dataset. Secondly, we determine the best form of sprinkler management according to the soil moisture results.

The rest of the paper is organized as follows. Section 2 discusses the related works regarding soil moisture monitoring through satellite data. The description of the methodology of our study is presented in Section 3. The results of the comparison between soil moisture monitoring through sensors and satellite images are provided in Section 4. Section 5 discusses our results. Lastly, Section 6 presents the conclusion and future work. 


\section{Related Work}

In this section, we outline the existing options for monitoring soil moisture with remote sensing resources. First, we describe the existing solutions, and then we analyze the main gap of each one. Finally, we detail the contributions of our paper based on the gaps of the existing proposals.

The use of satellite data in agriculture has expanded to include numerous functionalities. Deepak Gautam et al. reviewed the current remote sensing applications for agriculture [10]. Regarding monitoring soil moisture based on satellites, the authors comment on the use of L-band microwave radiometry such as the Soil Moisture Active Passive (SMAP) satellites from the NASA or the Soil Moisture Ocean Salinity (SMOS) sensor from ESA. There are, however, some limitations to this technique, such as the spatial resolution and the $5 \mathrm{~cm}$ depth of retrieval. Therefore, it is impossible to use this type of solution due to its low spatial resolution, which precludes its application in heterogenic scenarios such as golf courses, urban laws, or other similar areas. Another review of agricultural applications based on remote sensing is performed by L. Karthikeyan et al. [11]. The authors also comment on the Microwave Imaging Radiometer using Aperture Synthesis (MIRAS) and SMAP satellites. Furthermore, these satellites can also be used for other purposes, such as quantifying irrigation water use. Furthermore, the new applications and features of the Sentinel-2 satellites were discussed by Joel Segarra et al. [12]. The authors also compared the performance of other satellites to the Sentinel-2 and determined that the latter provides more capabilities for crop management and agricultural monitoring. Furthermore, the results show that the combination of other remote sensing techniques as well as field data is still necessary. Particularly, regarding soil moisture, determination coefficients between $65 \%$ and $83 \%$ were obtained from the combination of the NDVI obtained from Sentinel-2 and soil moisture models. The use of correlations between NDVI and soil moisture is not valid for our purpose. The main reason is that in the selected scenario is that the soil moisture changes faster than the NDVI. Therefore, when the change in NDVI is detected, the stress of the plats might be too high. An earlier detection method is required.

One of the most interesting functionalities is the detection of soil moisture and crop water content to determine irrigation needs without the need of deploying sensing devices. Chengyang $\mathrm{Xu}$ et al. performed data fusion to MODIS and Landsat images to determine the crop water content of soybean and corn crops [13]. A spatial resolution of $30 \mathrm{~m}$ and a revisit cycle of 16 days were the parameters for the Landsat image acquisition, and a spatial resolution of $500 \mathrm{~m}$ was used in the case of MODIS. Normalized Difference Water Index (NDWI) was obtained after performing the data fusion. Furthermore, measures were taken during the Soil Moisture Active Passive Validation Experiment to obtain the plan and canopy Vegetation Water Content (VWC). The results showed higher correlations for the soybean plants than that of the corn plants. As for [10], this solution cannot be applied in our scenario, given the spatial resolution of the remote sensing source selected. Hamed Adab et al. used machine learning to estimate soil moisture from satellite pictures from Landsat 8 with $30 \mathrm{~m}$ resolution [14]. The utilized techniques were Artificial Neural Networks (ANN), Random Forest (RF), Elastic Net Regression (EN), and Support Vector Machine (SVM). The results of the near-surface soil moisture showed that a Nash-Sutcliffe efficiency value of 0.73 was obtained for the RF technique, which was the highest value. Again, this proposal has a limitation regarding the spatial resolution of selected images (spatial resolution of $30 \mathrm{~m}$ ) compared with the used satellite (spatial resolution of $10 \mathrm{~m}$ and $20 \mathrm{~m}$ ). A study on different soil moisture indexes from SMOS and MODIS satellite data was presented by Miriam Pablos et al. [15]. The Soil Wetness Deficit Index (SWetDI), Soil Water Deficit Index (SWDI), Soil Moisture Deficit Index (SMDI), and the Soil Moisture Agricultural Drought Index (SMADI) were compared to the crop moisture index (CMI) and atmospheric water deficit (AWD) to determine the correlation and similarity of the studied indexes. The obtained results indicated that the SMADI and SWDI were the best options for drought monitoring, with correlation coefficients ranging between 0.5 and 0.8 . Anudeep Sure et al. studied soil moisture monitoring from the use of the microwave 
satellite sensors named Advanced Microwave Scattering Radiometer-2 (AMSR-2) and Soil Moisture Active Passive (SMAP) [16]. The study was performed for rice and wheat crops, and the soil wetness index was estimated for depths of 10 and $40 \mathrm{~cm}$. The coefficient of determination was calculated, obtaining a result of 0.9 for the SMAP sensor and 0.65 for the AMSR-2 sensor. Furthermore, a higher time delay was observed for the ascending pass. Moreover, Mireia Fontanet et al. performed a comparison of results from soil moisture sensors and results from the DISaggregation based on Physical and Theoretical scale Change (DISPATCH) algorithm, which SMOS and MODIS satellite data as well as NDVI and land surface temperature (LST) to estimate soil moisture [17]. The authors concluded that the DISPATCH algorithm performed appropriate estimations in the case of rainfall but not for sprinkler irrigation, where the water is distributed in a heterogeneous manner. Both [15] and [17] used MODIS, characterized by a low spatial resolution, which impedes the application of their results in our scenario. The same problems apply to the results of [16].

Lastly, Jesús Garrido-Rubio et al. presented a framework based on the Remote Sensingbased Soil Water Balance (RS-SWB) from satellite images and the dual crop coefficient from the FAO56 paper to calculate a Remote Sensing-based Irrigation Water Accounting (RS-IWA) metric [18]. For the plot scale, a 12\% root square mean error (RMSE) was obtained, comparing the results to those of the farmers. For the case of the water user association management, the obtained RMSE was 15\%. Therefore, the authors concluded that their proposed RS-IWA is appropriate to perform soil water balance estimations. Nevertheless, their proposal is specific for certain crops (wheat, maize, and barley). Therefore, its application in other vegetation such as grasses of urban lawns or golf courses or even for natural vegetation cannot be ensured.

Most studies on soil moisture that use satellite data are focused on crops such as wheat. However, this functionality is of interest for other types of vegetation, such as the grass in golf courses. In this paper, satellite data is analyzed to estimate soil moisture for a golf course composed of different types of grasses and areas with natural vegetation (which is not irrigated). Therefore, our results will be applicable for multiple scenarios. Moreover, we will include validation of proposed index or indexes by including data of other periods. The main contributions of this paper are the following ones:

- The combination of sensors and remote sensing generates a tailored index (or indexes) for estimating the soil moisture variations of the studied zone.

- The use of remote sensing imagery is characterized by higher spatial resolution $(10 \mathrm{~m}$ and $20 \mathrm{~m}$ ) than the most used imagery, characterized by lower spatial resolution such as MODIS.

- The data verification and clear presentation of indexes, $R$, and errors in both training and validation datasets.

- The heterogeneity of employed datasets is characterized by different vegetation and different soil types.

\section{Materials and Methods}

This section describes the sampling area, the sensor network, the image gathering, and the data processing followed to estimate the soil moisture in the golf course during the summer of 2021.

\subsection{Studied Zone}

We selected the "Encín Golf Course" located in Alcalá de Henares (Madrid, Spain) (Lat. $40^{\circ} 31^{\prime} 21^{\prime \prime}$; Long. $3^{\circ} 18^{\prime} 43^{\prime \prime}$ ) as the sampling area to deploy a batch of soil moisture sensors provided by PLANTAE. This region is characterized by very hot and short summers; and dry, very cold, and long winters. Generally, throughout the year, the temperature varies from 1 to $33{ }^{\circ} \mathrm{C}$. The temperature rarely cools down below $-4{ }^{\circ} \mathrm{C}$ or increases above $37^{\circ} \mathrm{C}$ [7]. Therefore, the golf manager must water the grass regularly in summer to keep it healthy and in optimal conditions to play. 
The golf course was built on a plot used for agriculture previously, on the upper terraces of the Henares River. Originally this area was characterized by a slope of less than $0.5 \%$ and surface horizons $\mathrm{Ap}$ and $\mathrm{AB}$ with the following characteristics: Ap between $0 \mathrm{~cm}$ and $18 \mathrm{~cm}$, clay loam texture (22.7\% gravel, $44.1 \%$ silt, $33.2 \%$ clay), weak structure, medium angular blocks, firm consistency when wet and hard when dry, thin and zonal clay films, few very fine pores, abundant roots of all sizes; and $A B$ between $18 \mathrm{~cm}$ and $32 \mathrm{~cm}$, clay loam texture ( $24.9 \%$ gravel, $41.1 \%$ silt, $34.0 \%$ clay), weak structure, medium angular blocks, firm consistency when wet and hard when dry, thin and zonal clay films, few pores fine and very fine, with an abundance of roots of all sizes [19]. In addition, it was designed in different areas, which account for different types of soil and grass management: (1) tee, fairway, and green, where the grass is tightly trimmed, regularly watered, and the soils are sandy; (2) rough surrounding the fairways, where the grass is kept longer, regularly watered and soils are sandy-clay; and (3) wild areas, with native plants and zero maintenance or watering, except from the rainfall (see Figure 1). Thus, only soil 1 and 2 were amended to adapt their texture to that required by the golf course designer.

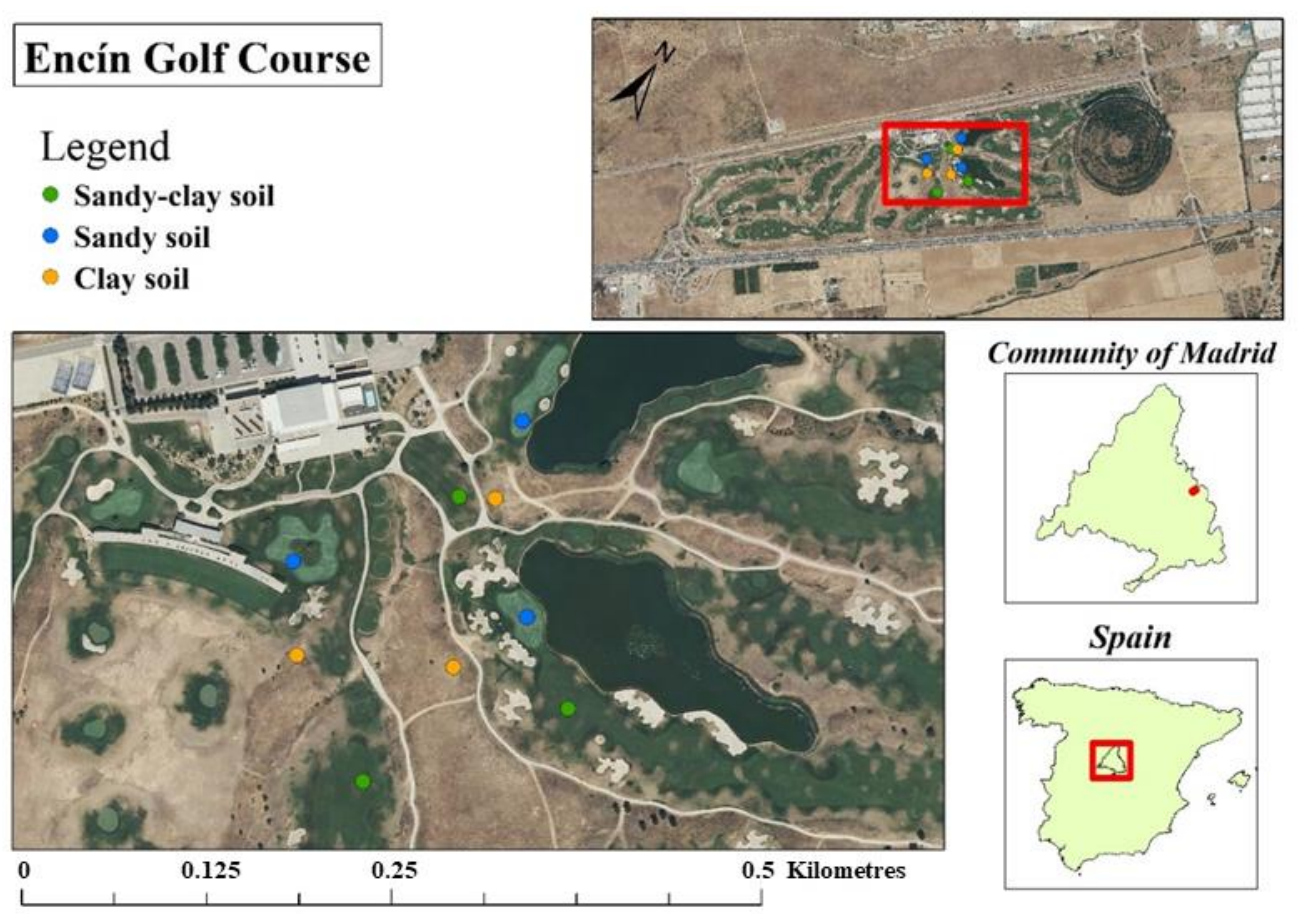

Figure 1. "Encín" Golf Course (Alcalá de Henares, Madrid, Spain) and sensors location.

We placed three sensors, see Figure 2a in different spots of every area, at a depth of $5 \mathrm{~cm}$ and covered by soil, to measure the shallow soil moisture. Thus, we have nine different sets of data. Small patches of grass were cut, and soil was removed to install the sensors; see Figure $2 \mathrm{~b}$. After placing the sensor, the hole was filled with soil, and the patch of grass was relocated. The soil moisture sensors, provided by PLANTAE, are a resistive sensor type, with temperature compensation [20]. The GPS coordinates and the sensor number were registered for each point. Then, they were configured to send data every $15 \mathrm{~min}$. The data was received in a hub placed close to the golf house. These records were uploaded and processed in a cloud service managed by PLANTAE. Data was provided as gravimetric water content (\%): the mass of water per mass of dry soil. The soil moisture sensors were calibrated by the service provider (PLANTAE), according to the texture of soil samples taken during the installation of the sensors. 


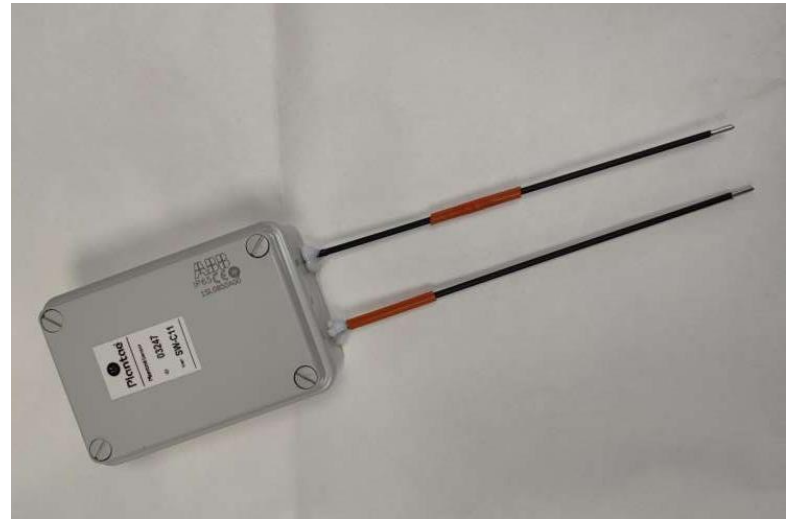

(a)

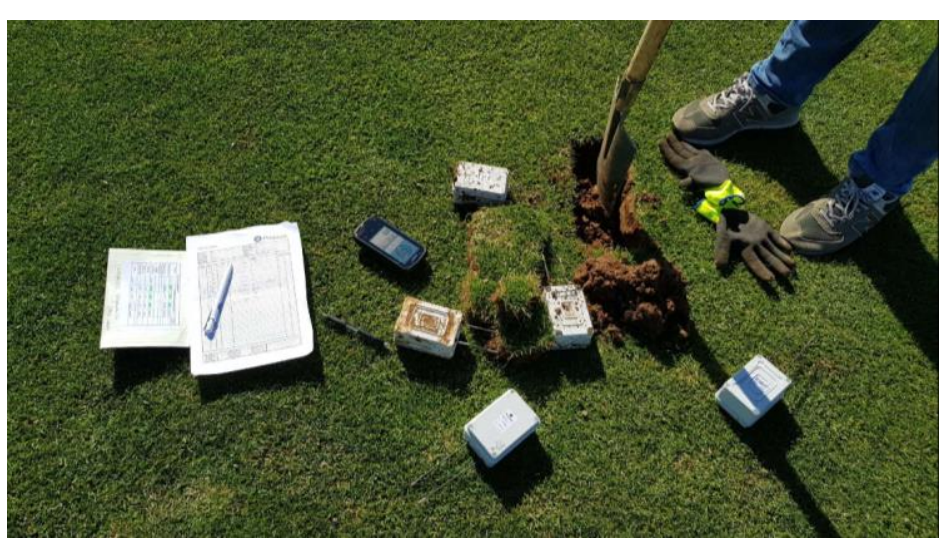

(b)

Figure 2. Details of the used sensors (a) the sensor, (b) installation of sensor in one of the selected greens.

The moisture values during the sampling period ranged between $5 \%$ and $35 \%$, depending on the irrigation, rainfall, and environmental temperature. The sandy and sandy-clay areas showed a lower humidity value (average 10\% to $15 \%$ ) compared to clay soil ones (average 20\%) due to the better drainage of these soils.

\subsection{Sentinel-2 Image Gathering}

To estimate and correlate the field data with the remote sensing data, we used Copernicus Sentinel-2 mission images provided by the European Space Agency. Sentinel-2 comprises a constellation of two polar-orbiting satellites placed in the same sun-synchronous orbit, phased at $180^{\circ}$ to each other. As they provide a ten-day revisit time with one satellite and five days with both satellites under cloud-free conditions, we gathered both Sentinel-2 A and Sentinel-2 B images. Therefore, the images available for the summer of 2021 include the following dates: 12th and 27th of June; 2nd, 12th, 17th, 22nd and 27th of July; 1st, 6th, 11th, 16th, 21st, 26th, and 31st of August; 5th and 29th of September. The initial and final dates were used for the verification of the regression models. The rest of the data were used for the generation of models.

We used both $10 \mathrm{~m}$ and $20 \mathrm{~m}$ resolution images. Sentinel- 2 offers information at three scales, $10 \mathrm{~m}, 20 \mathrm{~m}$, and $60 \mathrm{~m}$. At each scale, information from different bands is accessible. We consider that the images with resolution at $60 \mathrm{~m}$ have a too low spatial resolution to be used in this study due to the heterogeneity of the land covers in the golf course. The $10 \mathrm{~m}$ resolution images were available for band $2(490 \mathrm{~nm})$, band $3(560 \mathrm{~nm})$, band $4(665 \mathrm{~nm})$, and band $8(842 \mathrm{~nm})$ spectral bands. Meanwhile, the $20 \mathrm{~m}$ resolution images were available for the previous bands and band $5(705 \mathrm{~nm})$, band $6(740 \mathrm{~nm})$, band $7(783 \mathrm{~nm})$, band $8 \mathrm{a}$ $(865 \mathrm{~nm})$, band $11(1.610 \mathrm{~nm})$, and band $12(2.190 \mathrm{~nm})$. Although we consider that more accurate information will be obtained with information with a spatial resolution of $10 \mathrm{~m}$, the facto of having more available information (more bands) at $20 \mathrm{~m}$ justifies its inclusion. The statistical analyses do not join bands with different spatial resolutions to avoid the problems linked to uncertainties regarding differing pixel sizes.

\subsection{Data Processing}

Through the ArcMap [21] "Extract Values to Points" tool [22], we collected each pixel value from the multiple layers image (bands and days) at the specified sampling points (sensor). Data of different bands of the Sentinel-2 were processed together with the moisture values sensed by in-situ sensors. Soil moisture from the sensors was estimated as the average values gathered from 9:00 a.m. to 1:00 p.m. since the Sentinel-2 image was always taken at 10:56 a.m. The calculated average soil moisture value is used for the statistical analyses.

The data matrix was processed with Statgraphics Centurion XVIII [23] to analyze if there was any correlation between the moisture values and the values from the satellite 
images. First, general multivariate analyses, with all sorts of soil, and specific multivariate analyses, for individual sort of soil, were performed to find which satellite image bands correlate with the soil moisture. The multivariate analyses were performed according to the predefined options of Statgraphics Centurion XVIII [23]. No modifications were applied to the obtained results. The data of dispersion matrix and correlation matrix were used. All cases were included in the analyses. No outlier results were deleted for this initial test.

Then, simple and multiple regression models are compared according to the results of multivariate analyses. Regarding the simple regression models, a total of 27 possible regression models are evaluated. All of them include the use of a constant number, and the adjustment was performed according to the value of least squares. Concerning the multiple regression models, only linear regression is evaluated. The regression models will be calculated for all soil classes, a group of soils, or individual soils classes (sandy, sandy-clay, and clay) according to multivariate analyses. We assume $\mathrm{R}^{2}$ as the best indicator of the accuracy of the model. Attending to previous experiences, models characterized by $R^{2}$ higher than $50 \%$ should be considered as good models for this case due to the heterogeneity of the soil. This issue will be further analyzed in the discussion.

Once the mathematical models are obtained, the validation includes qualitative and quantitative analyses. The first one applies both mathematical models in ArcMap using the tool "Raster Calculator" [24], and results are checked and compared with other soil moisture indexes. The "Raster Calculator" is a simple tool that allows applying a mathematical model to one or more bands. This tool applies the mathematical model based on the pixel values of the bands included in the mathematical model generating a new raster. Then, the predicted value of soil moisture obtained in ArcMap was extracted and compared with the sensed one.

\section{Results}

In this section, we present the obtained results and correlations among the sensed data by the sensors and the information of remote sensing methods. First, we focus on bands with a spatial resolution of $10 \mathrm{~m}$. Following, the correlations obtained with bands with a spatial resolution of 10 and $20 \mathrm{~m}$ and the data sensed by the sensors are displayed. Finally, we present the verification of our models.

\subsection{Data of Bands with a Spatial Resolution of $10 \mathrm{~m}$ \\ 4.1.1. Multivariate Analyses}

The results of multivariate analyses are presented in Figure 3. In Figure 3, we can see the dispersion and the correlation matrix. In the correlation matrix, the values range from -1 to 1 ; the values closer to 0 indicate low correlations. The symbol (positive or negative) indicates if there is a positive or negative correlation between the variables. Moreover, the significance of the correlation, in terms of p-value is indicated in Figure 3. We can identify in Figure 3a the results of including all soil types, in Figure 3b the results for clay soil, in Figure $3 c$ the results for sandy soil, and in Figure $3 d$ the results for sandy-clay soil. According to the results, we can affirm that it is better to analyze the soils individually. For clay soil, band 4 has a negative correlation, and band 8 has a positive correlation, both statistically significant. Regarding clay-sandy soil, only band 8 correlates with the soil moisture values. In this case, is a positive and strong correlation. For the sandy soils, no correlation is found. 
(a)

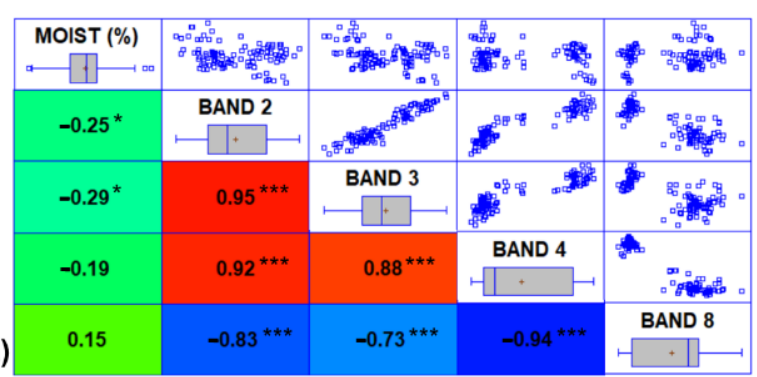

(c)

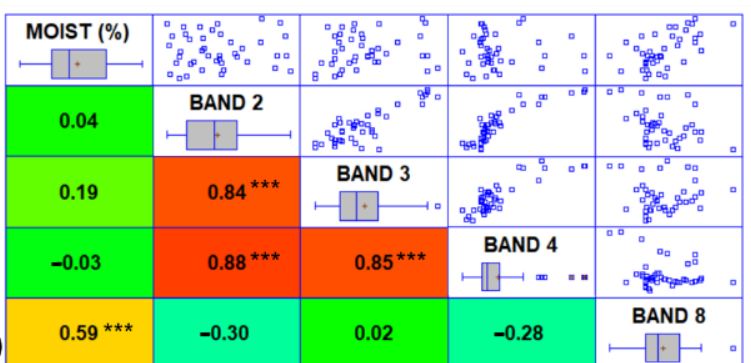

(b)

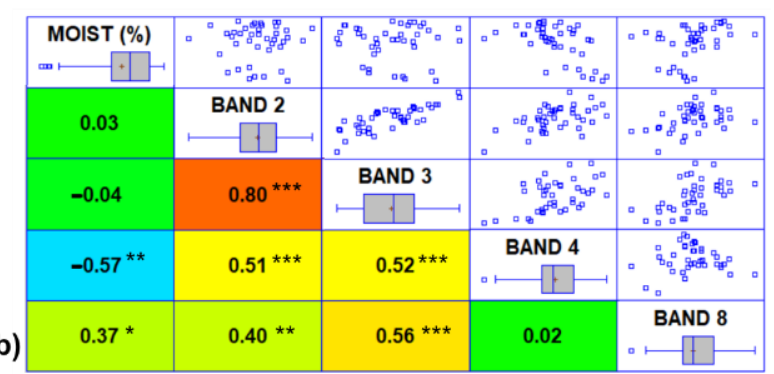

(d)

\begin{tabular}{|c|c|c|c|c|}
\hline MOIST (\%) & 0 & 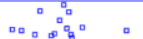 & & \\
\hline 1 & $\therefore$ & 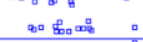 & $a^{\circ} \times x^{0}$ & $-00_{0}^{0} 000000$ \\
\hline-0.20 & BAND 2 & 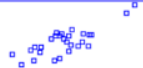 & 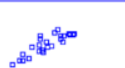 & 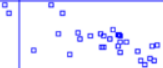 \\
\hline-0.17 & $0.78^{\star \star *}$ & BAND 3 & 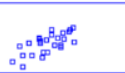 & 00 \\
\hline-0.27 & $0.92^{* * *}$ & $0.84^{\star \star \star}$ & BAND 4 & 00 \\
\hline 0.27 & $-0.57^{* *}$ & -0.10 & $-0.55^{*}$ & BAND 8 \\
\hline
\end{tabular}

Figure 3. Summary of multivariate analyses. (a) all soil types, (b) clay soil, (c) sandy soil, (d) sandy-clay soil. Significance levels (Sig): *** $p<0.001 ;{ }^{* *} p<0.010 ;{ }^{*} p<0.05$.

\subsubsection{Regression Models}

The following step is to analyze the regression models for the clay soil and sandy soil that allow estimating soil moisture based on remote sensing. Since for the sandy soil, there is only one band that shows a correlation with a $p$-value $>0.05$ we present the regression model for this band (Band 8). Regarding clay soil, we present the regression model with the band with the highest significance level (Band 4). Both simple regression models are represented in Figure 4 (Figure $4 \mathrm{a}$ for clay soil and Figure $4 \mathrm{~b}$ for sandy soil). In Figure 4 , we can see the mathematical model with the confidence and prediction intervals as well as the equation, the correlation coefficient, and the $\mathrm{R}^{2}$. In both cases, non-linear models are used to improve the accuracy of the regression, which increases the correlation coefficient described in Figure 3.
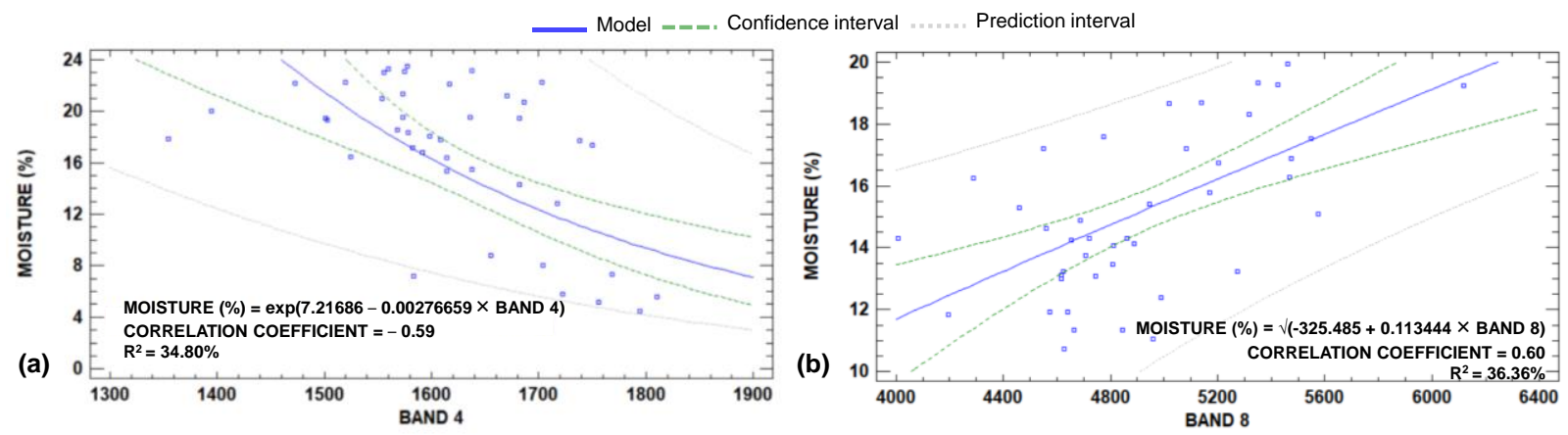

Figure 4. Simple Regression Models for (a) clay soil and (b) sandy soil for bands with $10 \mathrm{~m}$ of resolution.

On the other hand, a multiple regression model is calculated for clay soil since two bands have shown a correlation with $p$-value $>0.05$. The result of this multiple regression model, as observed vs. predicted soil moisture, can be seen in Figure 5 . We obtain better accuracy with the multiple regression model $\left(\mathrm{R}^{2}=0.47\right)$ for clay soil than for the simple regression model $\left(R^{2}=0.35\right)$. 


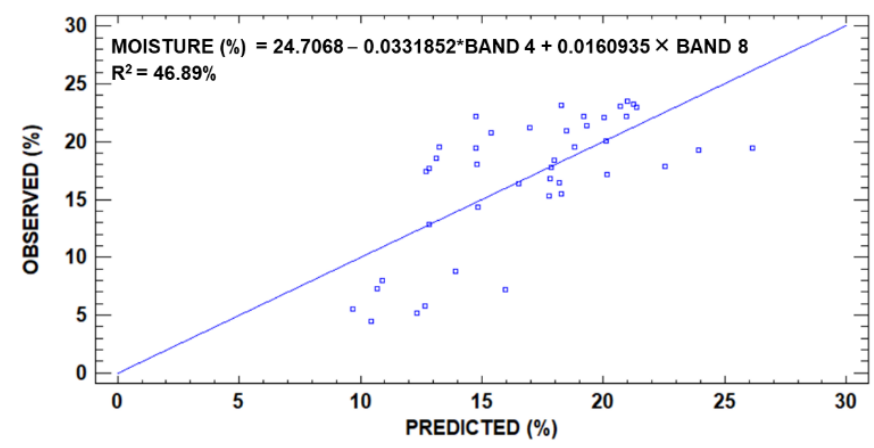

Figure 5. Multiple Regression Models for clay soil for bands with $10 \mathrm{~m}$ of resolution.

\subsection{Data of Bands with a Spatial Resolution of $20 \mathrm{~m}$}

\subsubsection{Multivariate Analyses}

As in the previous subsection, the results of the multivariate analyses performed with the Statgraphics Centurion XVIII [23] are presented in Figure 6. It is important to note that the pixel value of bands included in the previous subsection does not match the values in this subsection. For these analyses, we have used bands characterized the pixel value with a resolution of $20 \mathrm{~m}$; there are more available bands for this spatial resolution. As in Figure 3, in Figure 6 the dispersion and the correlation matrix can be seen. Nonetheless, in this case, we have included only the bands that correlate with the moisture since the complete table (with all the bands) is too big and provides too much useless information. As in the previous subsection, we can identify in Figure 6a the results of including all soil types, in Figure $6 \mathrm{~b}$ the results for sandy soil, and in Figure $6 \mathrm{c}$ the results for clay soil. No correlations are obtained for sandy-clay soil.

\section{Correlation coefficient: $-\mathbf{1 . 0}$}

1.0

(a)

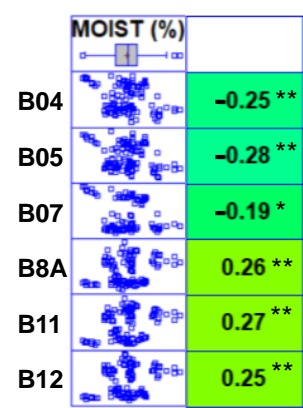

(b)

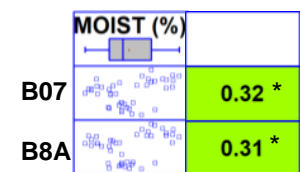

(c)

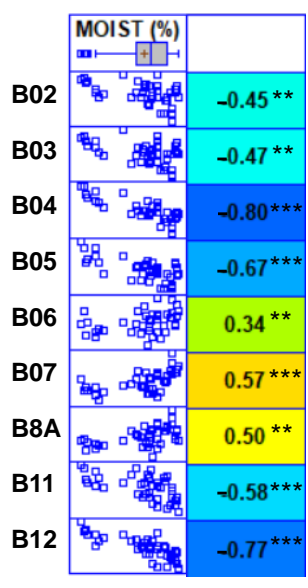

Figure 6. Summary of multivariate analyses. (a) all soil types, (b) sandy soil, and (c) clay soil. Significance levels (Sig): ${ }^{* *} p<0.001{ }^{* *} p<0.010{ }^{*} p<0.05$.

The most interesting results are linked to clay soil. The information contained in the satellite bands 4, 5, 11, and 12 presents a strong negative correlation with soil moisture, while; band 7 has a strong positive correlation. Other bands present correlation but with lower significance. For the other types of soil, no strong correlation (with high significance) is found.

\subsubsection{Regression Models}

Following, we analyze for the clay soil the regression models that allow estimating soil moisture based on remote sensing. In this case, no regression model for other types of soil is found. Simple and multiple regression models are calculated. For simple regression 
models, models based on band 4 and band 12 are displayed in Figure 7a,b, respectively. As in previous sections, in Figure 7, we can identify the regression model, the prediction and confidence intervals, correlation coefficient, and $\mathrm{R}^{2}$. Both bands, band 4 and band 12 , are combined for a multiple regression model; see Figure 8. In Figure 8, we can see the equation of correlation models, $R^{2}$, and predicted vs. observed results.
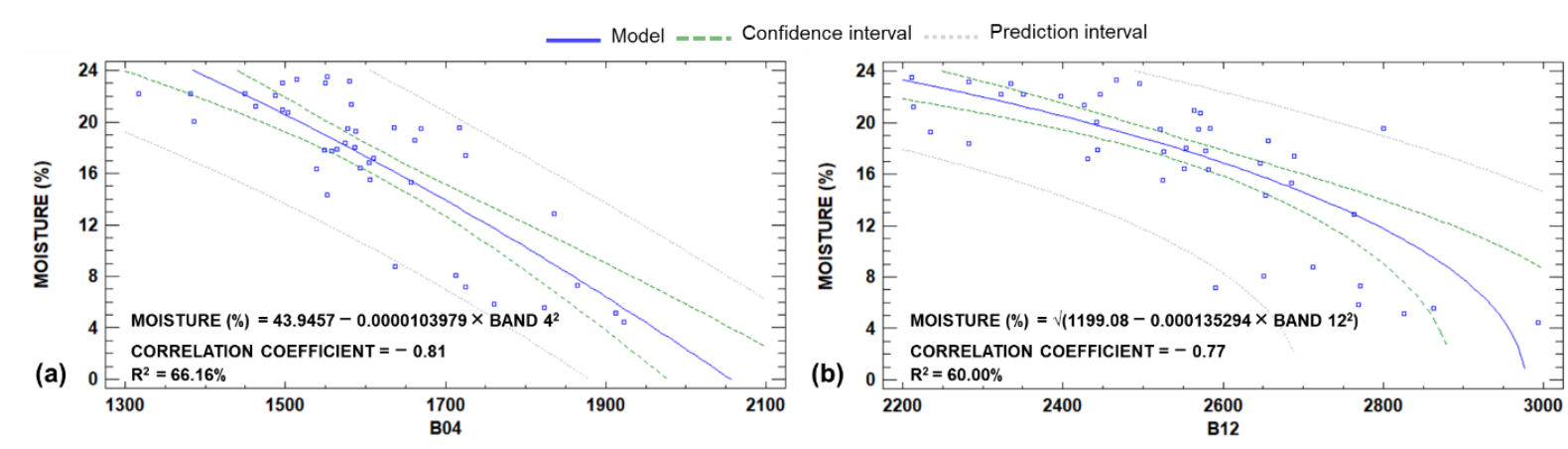

Figure 7. Simple Regression Models for clay soil with (a) band 4 and (b) band 12 for bands with 20 m of resolution.

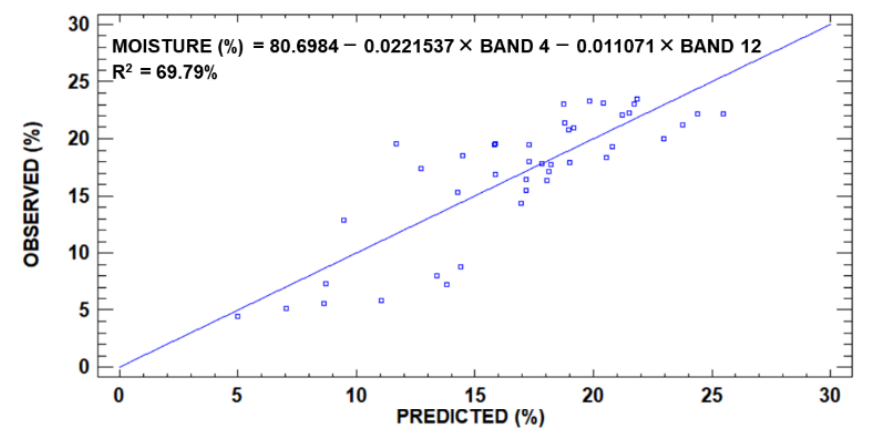

Figure 8. Multiple Regression Model for clay soil for bands with $20 \mathrm{~m}$ of resolution.

\subsection{Verification of Our Regression Models}

In this subsection, we verify our regression models by using data gathered just before and after the dataset used in the previous section. Used images correspond to 12 June 2021 and 20 September 2021, which are the closest dates without cloud coverage in the studied area. First, we show a visual verification which consists of applying the regression model to the area close to the golf course using ArcMap 10.4.1 software [21].

The results are visually analyzed as a qualitative verification, and the most relevant findings are in Figure 9, which includes the Orthophoto of the area [25]. We can see the differences in resolution in the models, especially in the detailed view in which the pixel resolution can be seen. Comparing the data, we can affirm that the results of the model calculated with a $10 \mathrm{~m}$ (presented in Figure 5) tend to estimate lower soil moisture. It is especially visible in the fairways and green areas. It must be noted that this model is designed for the natural areas with no irrigation or limited irrigation, and the results of irrigated areas might not be accurate. The areas in which the model is applied include both irrigated areas (as the greens and fairways of the golf course) and non-irrigated areas (such as some parts of the golf course, the surrounding fields of rainfed crops, and the natural areas as the mountains and the river). We can affirm that this area constitutes an excellent testbench to evaluate our results due to this heterogeneity. In both general and detailed view, we can see that the calculated soil moisture for the surroundings of the golf camps reflect the expected trends with (i) higher values in the areas close to the rives (sud-est of the picture), (ii) intermediate value in the natural areas with vegetation and, (iii) low values in areas such as olive orchards in which no vegetation retains the water. Regarding the detailed view, we see in detail the practice area composed of the driving range and the putting green. Both models' data accurately depicts the driving range's 
composition with higher soil moisture values in the green areas and their surroundings. Regarding the differences among dates, we can affirm that the most relevant difference in the analyzed periods is that the soil moisture level is lower in the second period. It is the expected change since after the summer, the whole area, most of it composed of natural areas and rainfed crops, has less soil moisture due to the reduction of rain and elevation of evapotranspiration during the summer. Therefore, based on our knowledge of the area and its direct observation during the studied period, we can affirm that the visual verification of results indicate that the predicted values are aligned with the expected variability of soil moisture in the golf course and their surroundings.

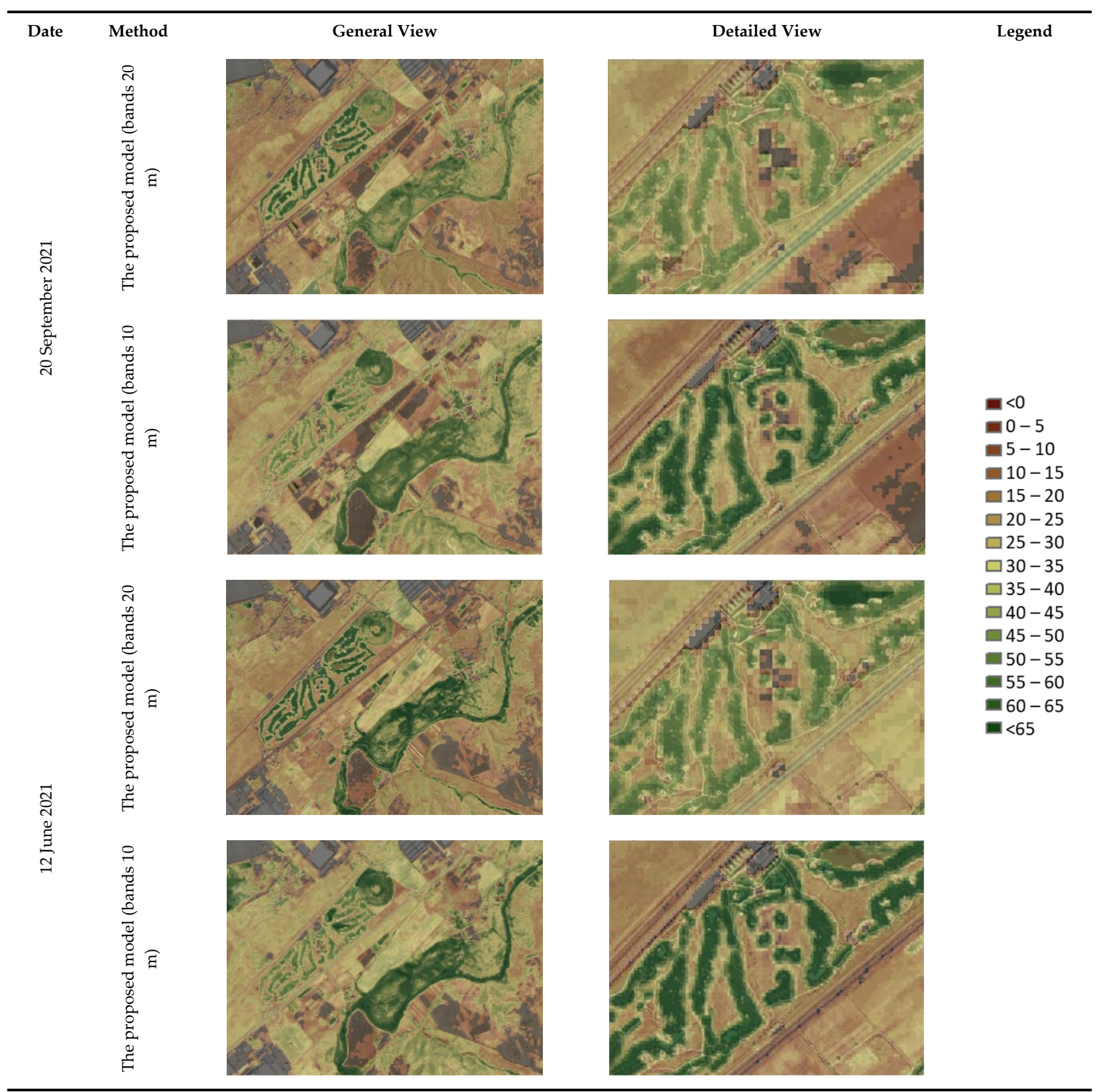

Figure 9. Comparison of proposed models. Models with transparency of 50\% and Orthophoto of 2019.

On the other hand, we perform a quantitative verification. For this verification, the soil moisture data of sensors from the clay soil of the golf course are compared with the results of generated models. In Figure 10a, we can see the six groups of data, which correspond to the 2 days and the 3 areas. In each data group, we can see in dark blu the 
value predicted by the mathematical model that uses bands with a resolution of $10 \mathrm{~m}$, and in light blue, the results for the model with the bands with $10 \mathrm{~m}$ resolution. In Figure 10b, the bivariate correlations between measured and estimated soil moisture values are shown. Meanwhile, the dark grey bars indicate the soil moisture values sensed by the sensors. In almost all cases, the mathematical model overestimates the soil moisture. The model calculated with the bands with a resolution of $10 \mathrm{~m}$ is the one with a higher overestimation. According to the temporal distribution of datasets and the variability of soil moisture and vegetation cover during the training and verification data set, a possible explanation for this overestimation can be proposed. Since the datasets used for the training stage correspond to the summer, the driest period, it is possible that the vegetation cover is greener in the validation dataset than in the training dataset, which causes this overestimation. The mean absolute error (MAE) is $12.5 \%$ and $8.4 \%$ for the models calculated with bands with resolutions of $10 \mathrm{~m}$ and $20 \mathrm{~m}$, respectively.

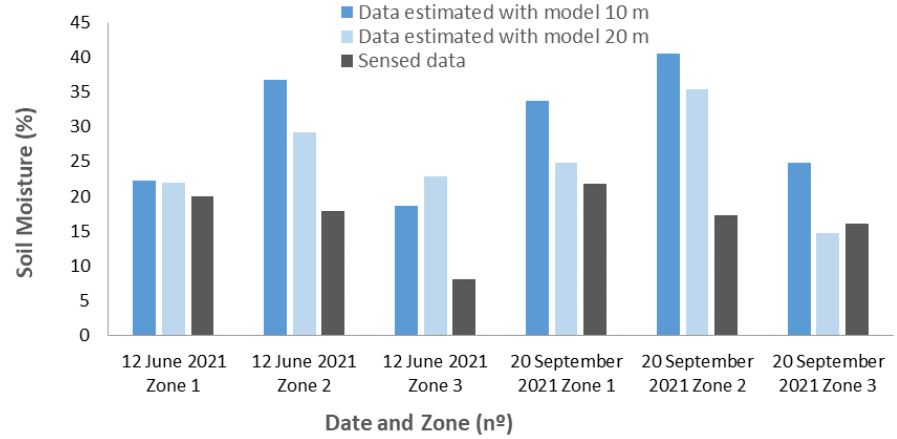

(a)

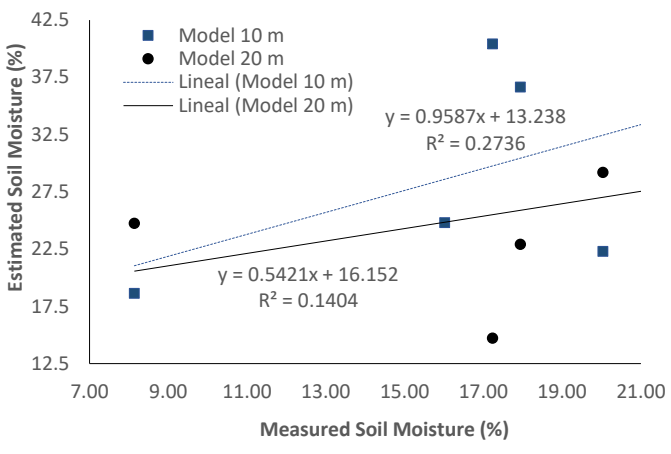

(b)

Figure 10. Results of quantitative verification in terms of (a) graphic bars of estimated and sensed data and (b) bivariate correlations.

\section{Discussion}

In this section, we discuss the results obtained in the aforementioned section. A comparison of our mathematical models with the existing soil moisture index that Sentinel Playground [26] provides is performed to assess the accuracy of our model compared with existing methods. Finally, the limitations of the present study are described.

\subsection{Comparison of Our Regression Models with Existing Moisture Indexes}

Regarding the existing soil moisture indexes, we follow the same procedure in the verifications, with quantitative and quantitative validation. For the qualitative comparison, we compare our results with the soil moisture index calculated by Sentinel Playground [26], see Figure 11.

In Figure 11, we can see that results for both days, 12 June 2021 and 20 September 2021 reflect the same trends observed in the data of soil moisture index. We can see those surroundings above the golf course have higher soil moisture values in both proposed and existing models in September than in June. On the other hand, the large field in the northwest of the picture is dryer in September, and this trend is reflected in both the proposed and existing index. Other areas in which the trends can be observed are the golf course itself and the round area in the northeast of the picture in which we identify a pivot that irrigates the crops (corn), and soil moisture was higher in September. Finally, an advantage of our index is that edifications present very different values, which allows extracting edifications from the analysis (black areas). Nonetheless, in some instances, fields with extremely low irrigations are considered as edifications. 


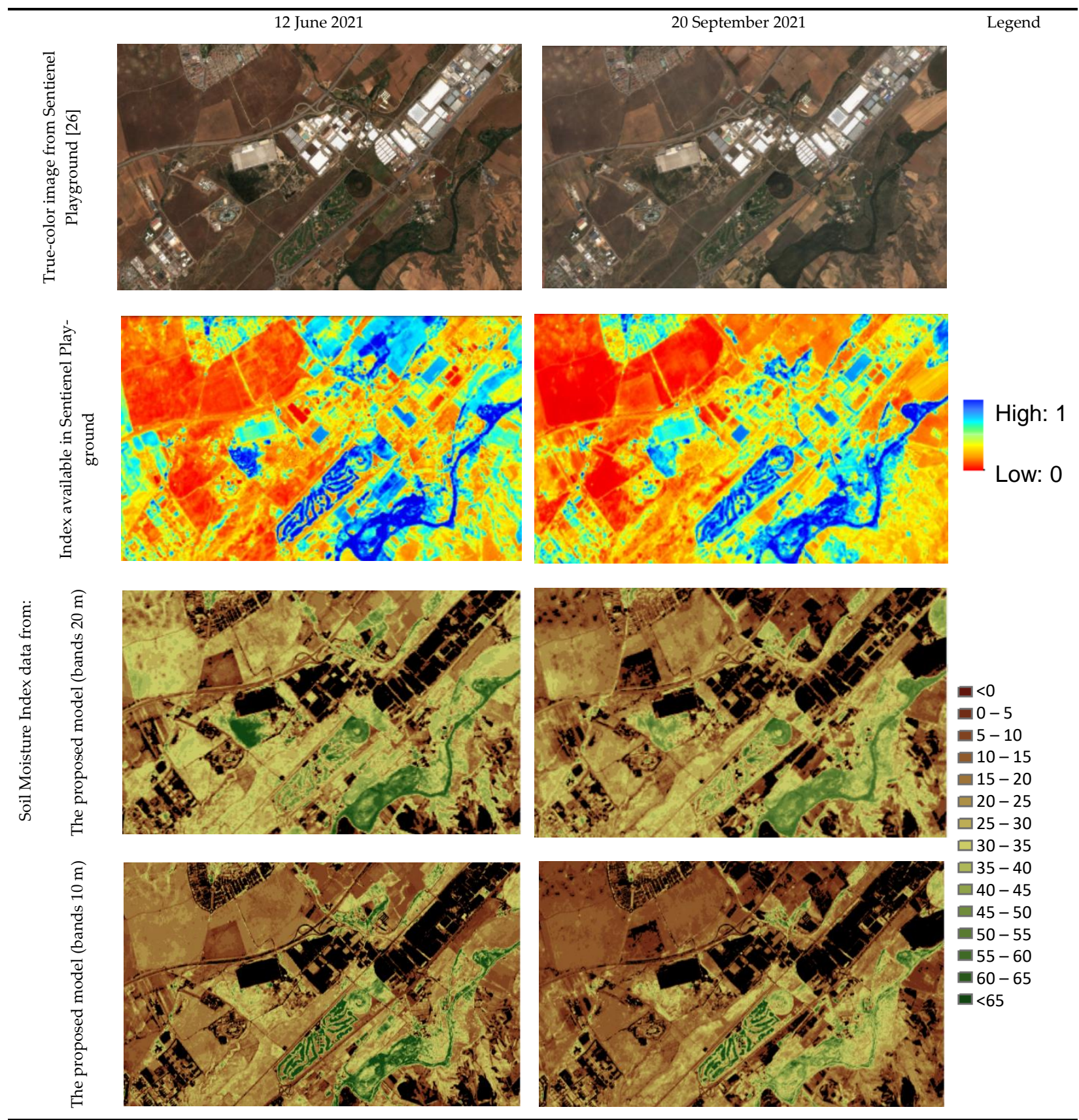

Figure 11. Comparison of proposed models with the model presented in Sentinel Playground.

The second part of the comparison is performed comparing the obtained $\mathrm{R}^{2}$ of the models and the MAE of the verification with the results of other authors. Regarding the papers presented in the related work [10-18], based on their information, none of them presents the modeled indexes, the $\mathrm{R}^{2}$, and MAEs to allow a comparison. Very few papers on this topic include details of the verification in these terms. Therefore, we have limited data to compare our results. In [27], Srivastava et al., the obtained MAEs are between 5.5\% and $8.2 \%$ using different spatial interpolation methods. In this case, the obtained regression model is characterized by an $\mathrm{R}^{2}$ of 0.64 . On the other hand, Lou et al. [28] used linear regression models to predict soil moisture among the six generated mathematical models. The maximum obtained $\mathrm{R}^{2}$ was 0.39 , and no information about MAE was given. In [29], Pal et al. estimate the soil moisture at $7.5 \mathrm{~cm}$ with different remote sensing sources, and the maximum obtained $\mathrm{R}^{2}$ was 0.28 and the MAEs range from $7 \%$ to $11 \%$ approximately (this data was obtained from a graphic and the exact values might be slightly different). 
According to the results of Sadeghi et al. [30], the greatest $R^{2}$ was 0.85 with an MAE of $2.4 \%$. Finally, Chen et al. in [31] obtained two correlations characterized by $\mathrm{R}^{2}$ of 0.45 to 0.49 and MAEs of $3 \%$ to $8 \%$. Those are the only found related work in which the $\mathrm{R}^{2}$ and MAEs are provided for the developed indexes.

In our calibrations, we obtained $\mathrm{R}^{2}$ of 0.46 and 0.70 with MAEs of $3.42 \%$ and $2.55 \%$ for models calculated with data of satellite with a spatial resolution of $10 \mathrm{~m}$ and $20 \mathrm{~m}$, respectively. In the verifications, the MAEs increased to 12.5 and $8.4 \%$. Thus, we can affirm that our models have similar characteristics to the existing models with the lowest MAEs in the calibrations and highest $R^{2}$. No papers provide information about the MAEs calculated during the verification phase. Therefore, it is not possible to perform this type of comparison. More information was found regarding other types of studies based on remote sensing data, which provide information about the $\mathrm{R}^{2}$ and MAEs of the training and validation dataset. In [32]. The authors measured the above-ground biomass of wheat; their results of the validation showed a modification of $\mathrm{R}^{2}$ (average reduction of $6 \%$ ) and MAEs (average increase of $11 \%$ ). Only in one of the eight cases, there was an improved $\mathrm{R}^{2}$ (with an increase of $10 \%$ ), but no improvement on its MAEs is reported. Another paper reports these differences, in [33] a decrease of $\mathrm{R}^{2}$ of $20 \%$ and $84 \%$ in the validation (according to of residual correction is applied or not). The change detected in the MAE in the verification dataset compared with the training dataset was an increase of $59 \%$ and $67 \%$, according to of residual correction is applied or not. In [34], authors show multiscale remote sensing to map cropland's spatial distribution and extent in the Sudanian savanna of West Africa. Their paper shows an increase of between 1.7 and $15.4 \%$ in the MAE values of the validation dataset for different training samples. The last example is shown in [35] in which chlorophyll content is estimated based on hyperspectral images. In the results, the authors indicate as average a reduction of $13 \%$ on the $\mathrm{R}^{2}$ in the validation dataset and an average increment of $12 \%$ in the MAEs. Nonetheless, authors found in some cases increments on the $\mathrm{R}^{2}$ of the validation dataset (from 0.57 to 0.78 ) and reductions on the MAEs (from 2.78 to 2.23 ).

\subsection{Limitation of Proposed Regression Models}

The main limitation of the proposed system is that it can only be applied in the areas classified as natural areas. No suitable models have been obtained which can monitor with an acceptable error the areas covered by grass in the golf course, the green areas, and the fairways. It is possible to have mathematical models for these cases, but the $\mathrm{R}^{2}$ of these models is around $24 \%$, and we assume that the errors are too high. Thus, we focused on the models for the natural areas within a golf course. Moreover, the application of the generated models can be applied to other areas with natural vegetation. Two key aspects cause the lack of models with appropriate $\mathrm{R}^{2}$ and MAEs.

On the one hand, there is a variability of soil moisture (from 6 to $19 \%$ approximately) in the greens, which is not correlated with changes in the grass. This is caused because the daily irrigation ensures that the plants $h$ an optimum vigor. The soil of the greens is sandy soil, which causes very fast drainage of water, which, together with the evapotranspiration, produces a fast decrease of soil moisture. This decrease of soil moisture is not related to the grass status, which neglects the correct detection of the soil moisture by observing grass coverage in this specific environment. Moreover, high spatial variability of soil moisture inside the green can be identified, as shown in [36].

On the other hand, in the fairways, we have a similar case. The grass coverage neglects the estimation of soil moisture because regardless of the instantaneous soil moisture value, the grass coverage aspect is stable in time. In this case, the situation is worsening than in the greens since the soil has lower homogeneity in the fairways, and it is formed by natural soil with an amendment of sand; an example of the heterogeneity of its soil moisture can be seen in $[37,38]$. Moreover, the grass coverage in the fairways is far less homogeneous than in the greens, both in the temporal and spatial gradient. Regarding the temporal variability, an example can be seen in [6]. In the greens, the grass is kept at a given height, and they 
are mowed periodically, ensuring the same grass height along the green and along the time. In the fairways, we do not have this homogeneity.

Regarding the use of NDV and related indexes to evaluate the soil moisture in greens and fairway areas of the golf course, as shown in [12], recently published results show no correlation between NDVI and soil moisture. Although [39] showed a clear correlation between NDVI and soil moisture in grasses with different water stress, Ref. [40] indicated that there is no correlation when no continuous stress is applied. The authors set in [40] that this is because in short periods of time, even though the soil moisture decreases after irrigating, the NDVI remains uniform. Moreover, they highlight the difficulties of obtaining data that prove the decrease of soil moisture in a short period of time due to the high heterogeneity of soil.

Finally, the MAEs of the verification process is higher than the MAEs of the calibration. The increase of MAEs in the verification might be caused by changes in the land coverage, which are not considered in the initial model. Therefore, it will be necessary to gather and analyze more data along the year to estimate if the proposed soil moisture model should be reformulated to include other seasons. Another option is to generate specific models for each season or period.

\section{Conclusions}

The estimation of accurate soil moisture using satellite imagery is essential for evaluating irrigation efficiency. It can be applied to several areas such as in the urban lawn, golf courses, agriculture, or at a higher scale considering a whole river basin. Nonetheless, the existing proposed models have relatively low accuracies.

This paper shows the combined use of remote sensing and a soil moisture sensor network to generate soil sensor indexes based on satellite imagery. Our results indicate that it is feasible to evaluate the soil moisture at different points of the golf course to achieve better water efficiency by using Sentinel-2 images. Nonetheless, indexes offered accurate results only in the natural soil, precluding remote soil moisture estimation in the fairways and greens. The accuracy of obtained models upgrades the existing solutions based on the $\mathrm{R}^{2}$ and the MAEs of the calibration dataset. We added a validation dataset to verify our findings. The validation indicated that the model obtained with bands at $20 \mathrm{~m}$ has greater MAE than the training dataset. This aspect was not considered in previous contributions, and it is essential to ensure its application to new areas. To verify our results, a comparison with other indexes is performed. The indexes were applied to the nearby area of the golf course, and the obtained results correspond to the observed changes in the different land uses.

As future work, we will include data of other seasons to decrease the MAEs of the validation dataset. Our main objective with future work is to evaluate the option of creating seasonal soil moisture indexes. Moreover, other remote sensing sources will be combined with Sentinel-2 data to attain the generation of soil moisture models suitable for fairways and green areas.

Author Contributions: Conceptualisation, L.P. and D.M.-C.; methodology, L.P.; software, L.P. and D.M.-C.; validation, P.V.M., J.F.M. and J.L.; formal analysis, L.P.; data curation, L.P.; writing—original draft preparation, L.P., L.G. and D.M.-C.; writing-review and editing, L.G. and L.P.; supervision, P.V.M., J.F.M. and J.L.; project administration, P.V.M.; funding acquisition, P.V.M., J.F.M. and J.L. All authors have read and agreed to the published version of the manuscript.

Funding: This research was partially funded by project PDR18-XEROCESPED, under the PDR-CM 2014-2020, by the EU (European Agricultural Fund for Rural Development, EAFRD), Ministerio de Agricultura, Pesca y Alimentación (MAPA) and Comunidad de Madrid regional government through IMIDRA, by the "Programa Estatal de I+D+i Orientada a los Retos de la Sociedad, en el marco del Plan Estatal de Investigación Científica y Técnica y de Innovación 2017-2020" (Project code: PID2020-114467RR-C33), and by "Proyectos de innovación de interés general por grupos operativos de la Asociación Europea para la Innovación en materia de productividad y sostenibilidad agrícolas (AEI-Agri)" in the framework "Programa Nacional de Desarrollo Rural 2014-2020", GO TECNOGAR, 
and by Conselleria de Educación, Cultura y Deporte, through "Subvenciones para la contratación de personal investigador en fase postdoctoral" APOSTD/2019/04.

Institutional Review Board Statement: Not applicable.

Informed Consent Statement: Not applicable.

Data Availability Statement: The data presented in this study are available on request from the corresponding author. The data are not publicly available due to privacy constraints.

Conflicts of Interest: The authors declare no conflict of interest.

\section{References}

1. Bahri, A.; Basset, C.; Queslati, F.; Brissaud, F. Reuse of reclaimed wastewater for golf course irrigation in Tunisia. Water Sci. Technol. 2001, 43, 117-124. [CrossRef]

2. Salgot, M.; Priestley, G.K.; Folch, M. Golf Course Irrigation with Reclaimed Water in the Mediterranean: A Risk Management Matter. Water 2012, 4, 389-429. [CrossRef]

3. Ezhilazhahi, A.M.; Bhuvaneswari, P.T.V. IoT enabled plant soil moisture monitoring using wireless sensor networks. In Proceedings of the 2017 Third International Conference on Sensing, Signal Processing and Security (ICSSS), Chennai, India, 4-5 May 2017; pp. 345-349.

4. Ferrarezi, R.S.; Nogueira, T.A.R.; Zepeda, S.G.C. Performance of Soil Moisture Sensors in Florida Sandy Soils. Water 2020, $12,358$. [CrossRef]

5. Manneback, P.; Lebau, F. Irrigation Pivot-Center Connected at Low Cost for the Reduction of Crop Water Requirements. In Proceedings of the International Conference on Advanced Communication Technologies and Networking, Marrakech, Morocco, 2-4 April 2018.

6. Vicente, J.; Rocha, R.; Neves, R. GolfSense: A golf course WSN monitoring application. In Proceedings of the 2010 International Conference on Computer Engineering \& Systems, Cairo, Egypt, 30 November-2 December 2010; pp. 152-157.

7. Parra, L.; Mostaza-Colado, D.; Yousfi, S.; Marín, J.F.; Mauri, P.V.; Lloret, J. Drone RGB Images as a Reliable Information Source to Determine Legumes Establishment Success. Drones 2021, 5, 79. [CrossRef]

8. Wu, K.; Rodriguez, G.A.; Zajc, M.; Jacquemin, E.; Clément, M.; de Coster, A.; Lambot, S. A new drone-borne GPR for soil moisture mapping. Remote Sens. Environ. 2019, 235, 111456. [CrossRef]

9. García, L.; Parra, L.; Jimenez, J.M.; Lloret, J.; Mauri, P.V.; Lorenz, P. DronAway: A Proposal on the Use of Remote Sensing Drones as Mobile Gateway for WSN in Precision Agriculture. Appl. Sci. 2020, 10, 6668. [CrossRef]

10. Gautam, D.; Pagay, V. A Review of Current and Potential Applications of Remote Sensing to Study the Water Status of Horticultural Crops. Agronomy 2020, 10, 140. [CrossRef]

11. Karthikeyan, L.; Chawla, I.; Mishra, A.K. A review on remote sensing applications in agriculture for food security: Crop growth and yield, irrigation, and crop losses. J. Hydrol. 2020, 586, 124905. [CrossRef]

12. Segarra, J.; Buchaillot, M.L.; Araus, J.L.; Kefauver, S.C. Remote Sensing for Precision Agriculture: Sentinel-2 Improved Features and Applications. Agronomy 2020, 10, 641. [CrossRef]

13. Xu, C.; Qu, J.; Hao, X.; Cosh, M.H.; Zhu, Z.; Gutenberg, L. Monitoring crop water content for corn and soybean fields through data fusion of MODIS and Landsat measurements in Iowa. Agric. Water Manag. 2020, 227, 105844. [CrossRef]

14. Adab, H.; Morbidelli, R.; Saltalippi, C.; Moradian, M.; Ghalhari, G.A.F. Machine Learning to Estimate Surface Soil Moisture from Remote Sensing Data. Water 2020, 12, 3223. [CrossRef]

15. Pablos, M.; Martínez-Fernández, J.; Sánchez, N.; González-Zamora, A. Temporal and Spatial Comparison of Agricultural Drought Indices from Moderate Resolution Satellite Soil Moisture Data Over Northwest Spain. Remote Sens. 2017, 9, 1169. [CrossRef]

16. Sure, A.; Dikshit, O. Estimation of root zone soil moisture using passive microwave remote sensing: A case study for rice and wheat crops for three states in the Indo-Gangetic basin. J. Environ. Manag. 2019, 234, 75-89. [CrossRef]

17. Fontanet, M.; Fernàndez-Garcia, D.; Ferrer, F. The value of satellite remote sensing soil moisture data and the DISPATCH algorithm in irrigation fields. Hydrol. Earth Syst. Sci. Vil. 2018, 22, 5889-5900. [CrossRef]

18. Garrido-Rubio, J.; González-Piqueras, J.; Campos, I.; Osann, A.; González-Gómez, L.; Calera, A. Remote sensing-based soil water balance for irrigation water accounting at plot and water user association management scale. Agric. Water Manag. Vil. 2020, 238, 106236. [CrossRef]

19. Bienes, R.; Fernández-Quintanilla, C.; Gallego, J.; Hernanz, J.L.; Martínez, T.; Mauri, P.; Vergara, G. El Encín: Clima, Suelo y Vegetación; Consejería de Medio Ambiente, Dirección General de Educación y Promoción Ambiental: Comunidad de Madrid, Spain, 2000; ISBN 84-4511865-X.

20. ArcMap Software. Available online: https://www.esri.com/en-us/arcgis/products/arcgis-pro/overview (accessed on 20 October 2021).

21. Soil Moisture Sensor Information of Provider. Available online: https://plantae.garden/products/station/ (accessed on 29 November 2021).

22. Operation Description of Extract Values to Poits Tool from ArcMap. Available online: https://desktop.arcgis.com/en/arcmap/ 10.3/tools/spatial-analyst-toolbox/extract-values-to-points.htm (accessed on 29 November 2021). 
23. Statgraphics Centurion XVIII Software. Available online: https://statgraphics.net/ (accessed on 20 October 2021).

24. Operation Description of Raster Calculator Tool from ArcMap. Available online: https://desktop.arcgis.com/en/arcmap/10.3 /tools/spatial-analyst-toolbox/how-raster-calculator-works.htm (accessed on 29 November 2021).

25. Sentinel Playground Webpage. Available online: https://apps.sentinel-hub.com/sentinel-playground (accessed on 20 October 2021).

26. WMS of Orthophoto of PNOA. Available online: https://www.ign.es $/$ wms-inspire/pnoa-ma?request=GetCapabilities\&service= WMS (accessed on 20 October 2021).

27. Srivastava, P.K.; Pandey, P.C.; Petropoulos, G.P.; Kourgialas, N.N.; Pandey, V.; Singh, U. GIS and remote sensing aided information for soil moisture estimation: A comparative study of interpolation techniques. Resources 2019, 8, 70. [CrossRef]

28. Luo, W.; Xu, X.; Liu, W.; Liu, M.; Li, Z.; Peng, T.; Chaohao, X.; Yaohua, Z.; Zhang, R. UAV based soil moisture remote sensing in a karst mountainous catchment. Catena 2019, 174, 478-489. [CrossRef]

29. Pal, M.; Maity, R. Assimilation of remote sensing based surface soil moisture to develop a spatially varying vertical soil moisture profile database for entire Indian mainland. J. Hydrol. 2021, 601, 126807. [CrossRef]

30. Piles, M.; Camps, A.; Vall-Llossera, M.; Corbella, I.; Panciera, R.; Rudiger, C.; Kerr, Y.H.; Walker, J. Downscaling SMOS-derived soil moisture using MODIS visible/infrared data. IEEE Trans. Geosci. Remote Sens. 2011, 49, 3156-3166. [CrossRef]

31. Chen, Q.; Miao, F.; Wang, H.; Xu, Z.X.; Tang, Z.; Yang, L.; Qi, S. Downscaling of satellite remote sensing soil moisture products over the Tibetan Plateau based on the random forest algorithm: Preliminary results. Earth Space Sci. 2020, 7, e2020EA001265. [CrossRef]

32. Yue, J.; Yang, G.; Li, C.; Li, Z.; Wang, Y.; Feng, H.; Xu, B. Estimation of winter wheat above-ground biomass using unmanned aerial vehicle-based snapshot hyperspectral sensor and crop height improved models. Remote Sens. 2017, 9, 708. [CrossRef]

33. Jing, W.; Yang, Y.; Yue, X.; Zhao, X. A comparison of different regression algorithms for downscaling monthly satellite-based precipitation over North China. Remote Sens. 2016, 8, 835. [CrossRef]

34. Forkuor, G.; Conrad, C.; Thiel, M.; Zoungrana, B.J.; Tondoh, J.E. Multiscale remote sensing to map the spatial distribution and extent of cropland in the Sudanian Savanna of West Africa. Remote Sens. 2017, 9, 839. [CrossRef]

35. An, G.; Xing, M.; He, B.; Liao, C.; Huang, X.; Shang, J.; Kang, H. Using machine learning for estimating rice chlorophyll content from in situ hyperspectral data. Remote Sens. 2020, 12, 3104. [CrossRef]

36. Kieffer, D.L.; O'Connor, T.S. Managing soil moisture on golf greens using a portable wave reflectometer. In Proceedings of the Annual Irrigation Show, San Diego, CA, USA, 9-11 December 2007.

37. Kieffer, D.L.; Huck, M. A Comparison of Fairway Distribution Uniformity Computed with Catch Can Data and with Soil Moisture Data from Three Sampling Depths. In Proceedings of the 29th Annual Irrigation Show, California, CA, USA, 2-4 November 2008; Volume 2.

38. Carrow, R.N.; Cline, V. Precision Turf Management: A New Water Audit Based on Soil Moisture; Golf Course Management Magazine: USA, 2011; pp. 76-82.

39. Marín, J.; Yousfi, S.; Mauri, P.V.; Parra, L.; Lloret, J.; Masaguer, A. RGB vegetation indices, NDVI, and biomass as indicators to evaluate C3 and C4 turfgrass under different water conditions. Sustainability 2020, 12, 2160. [CrossRef]

40. Mauri, P.V.; Parra, L.; Yousfi, S.; Lloret, J.; Marin, J.F. Evaluating the Effects of Environmental Conditions on Sensed Parameters for Green Areas Monitoring and Smart Irrigation Systems. Sensors 2021, 21, 2255. [CrossRef] [PubMed] 